\title{
KIT NP_000213.1:p.V852I
}

National Cancer Institute

\section{Source}

National Cancer Institute. KIT NP 000213.1:p.V8521. NCI Thesaurus. Code C155721.

A change in the amino acid residue at position 852 in the mast/stem cell growth factor receptor Kit protein where valine has been replaced by isoleucine. 